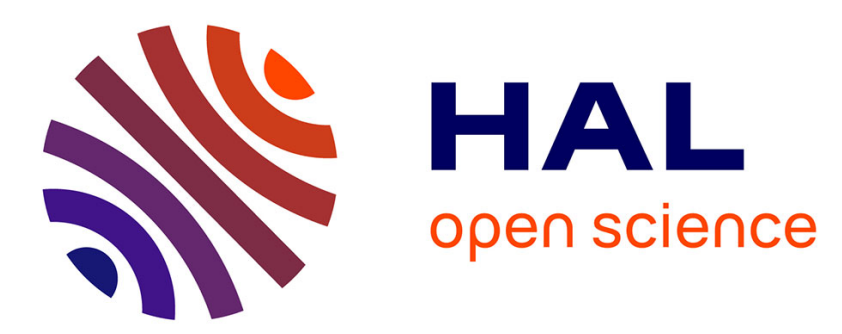

\title{
Modeling of adsorption of CO2 in the deformed pores of MIL-53(Al)
}

\author{
Ege Dundar, Nicolas Chanut, Filip Formalik, P. Boulet, Philip Llewellyn, \\ Bogdan Kuchta
}

\section{> To cite this version:}

Ege Dundar, Nicolas Chanut, Filip Formalik, P. Boulet, Philip Llewellyn, et al.. Modeling of adsorption of CO2 in the deformed pores of MIL-53(Al). Journal of Molecular Modeling, 2017, 23 (4), 10.1007/s00894-017-3281-4 . hal-01741436

\section{HAL Id: hal-01741436 \\ https://hal-amu.archives-ouvertes.fr/hal-01741436}

Submitted on 9 May 2018

HAL is a multi-disciplinary open access archive for the deposit and dissemination of scientific research documents, whether they are published or not. The documents may come from teaching and research institutions in France or abroad, or from public or private research centers.
L'archive ouverte pluridisciplinaire HAL, est destinée au dépôt et à la diffusion de documents scientifiques de niveau recherche, publiés ou non, émanant des établissements d'enseignement et de recherche français ou étrangers, des laboratoires publics ou privés. 


\title{
Modeling of adsorption of $\mathrm{CO}_{2}$ in the deformed pores of MIL-53(Al)
}

\author{
Ege Dundar ${ }^{1}$, Nicolas Chanut ${ }^{1}$, Pascal Boulet ${ }^{1}$, Philip L. Llewellyn ${ }^{1}$, Bogdan \\ Kuchta $^{1,2}$ \\ ${ }^{1}$ Laboratoire MADIREL, Aix-Marseille Université - CNRS UMR 7246, 13396 Marseille, France \\ ${ }^{2}$ Group of Bioprocess and Biomedical Engineering, Wroclaw University of Science and Technology, 50-370 \\ Wroclaw, Poland,
}

\begin{abstract}
Carbon dioxide is a greenhouse gas implicated in global warming [1] but also used in existing hydrogen production processes [2]. Therefore, with a future world economy based on hydrogen as an energy vector, coupled with recent commitments to the Kyoto Agreement whereby efforts must be made to reduce $\mathrm{CO}_{2}$ emissions, there is a need for materials to efficiently capture and store $\mathrm{CO}_{2}$ [3]. The MIL series of hybrid porous frameworks are candidates for the purpose of $\mathrm{CO}_{2}$ adsorption. In particular, the breathing MIL-53 structures are of special interest because their adsorption properties can be modulated by applying external pressure to modify pore geometry $[3,4]$.
\end{abstract}

Molecular simulations were performed to predict $\mathrm{CO}_{2}$ adsorption in flexible metal-organic frameworks. For this purpose, a generic force field was fitted to our experimental data to describe the non-bonded (electrostatic and Van der Waals) interactions between the $\mathrm{CO}_{2}$ molecules and the large pore (lp) and narrow pore (np) forms of the MIL-53(Al) framework. With this validated force field, it will be possible to predict $\mathrm{CO}_{2}$ uptake and enthalpy of adsorption at various applied external pressures that will modify the structure's pore configuration and allow us to have more control over the adsorption/desorption process . This will be done in future work by creating rigid intermediate structure forms between the $1 p$ and np shapes, and simulating adsorption of $\mathrm{CO}_{2}$ in each of them.

In parallel of our modeling strategy, we have devised an experimental device in which it is possible to modulate the porosity of the MIL-53 material with the aid of external mechanical pressure. Equally, calorimetry experiments have been carried out on the unconstrained material to directly measure the adsorption enthalpies. This set of experiments allows a comparison of the isotherms on the material constrained to various mechanical pressures, and the enthalpies on the non-constrained material, with the results obtained by molecular 
simulation. This joint experimental-computational approach allows for us to further understand this flexible class of materials and is a way forward to understanding the possibility to optimize pore size for specific gas separations.

\subsection{Introduction}

With recent global commitments to reduce greenhouse emissions, there is an increasing need for high quality materials capable of capturing and storing harmful gases like $\mathrm{CO}_{2}{ }^{1}$. Therefore, great attention has lately been given to the development and elaboration of porous materials such as metal-organic frameworks (MOFs). These are versatile, chemically and thermally robust materials containing reactive sites and large pores with high surface areas ${ }^{2,3}$. Because of these important features, MOFs are able to efficiently capture and release guest molecules and thus find use in various industrial applications like gas storage/separation, catalysis, and biomedicine ${ }^{3}$. Some MOFs have been known to show selective flexibility during gas adsorption via unusual breathing ${ }^{4}$ and gate opening process ${ }^{5}$ properties. The MIL53 (Cr, Al) (Matériaux de l'Institut Lavoisier) structures synthesized by the group of Férey are among the most interesting structures displaying these features because of their high uptake capacity for gases like $\mathrm{CO}_{2}$ and $\mathrm{CH}_{4}{ }^{6}$. Concerning $\mathrm{CO}_{2}$ particularly, an unusual microscopic adsorption behavior in the aluminum and chromium-containing MIL-53 structures has been reported, based on microcalorimetric measurements. This behavior was associated with a breathing mechanism of the framework where the structure is able to reversibly change its configuration from a narrow pore (np) form to a large pore (lp) form ${ }^{6}$. Although the signature of these structural changes can be detected experimentally, the microscopic mechanism involved in the transitions is too fast to be well understood.

To date, computational methods have played a significant role in elucidating the mechanism of adsorption at an atomistic level and in providing insight on the microscopic arrangement of the adsorbates in the flexible framework pores. Ramsahye et al ${ }^{1}$ have focused on the theoretical study of $\mathrm{CO}_{2}$ adsorption in MIL-53 (Al) using Grand Canonical Monte Carlo (GCMC) simulations based on atomistic potential parameters and a partial charge model. By comparing the simulated isotherms and differential enthalpies of adsorption with experimental data they were able to observe that at pressures below 0.1 bar and above 6 bar, the framework takes the $1 p$ form while between 0.25 bar and 6 bar the $n p$ form is present. In their case the 
framework was considered rigid with the constituent atoms positioned at the coordinates reported by crystallography. In order to properly model the breathing of the MIL-53(Cr) structure, Salles et al ${ }^{2}$ extended their simulations to encompass molecular dynamics. The force field thus had to be modified and included forces like bond potential, bending potential and torsion potential, in addition to the non-bonded Lennard-Jones and electrostatic interactions. By doing this the group successfully captured the two-step structural switching, and correctly reproduced the empty large and narrow-pore structures as well as the large magnitude of the breathing in presence of $\mathrm{CO}_{2}$. More recently, Garcia-Pérez et al have reproduced adsorption and simulated diffusion of $\mathrm{CO}_{2}$ and $\mathrm{CH}_{4}$ in the flexible $\mathrm{NH}_{2}$-MIL53(Al) while using a rigid force field and a minimum number of experiments ${ }^{7}$. Their twostep process consisted of an optimization of the interactions between the $\mathrm{CO}_{2}$ molecules and the bridging hydroxyl groups of the framework, followed by the use of a linear combination of the $\mathrm{np}$ and $\mathrm{lp}$ forms based on experimental results.

The goal of this work was to verify whether a validated force field found in the literature can effectively predict our own experimental adsorption isotherms and enthalpy of adsorption measurements for the same gas, same adsorbent, in the same thermodynamic conditions. In the eventuality that it can, our goal is to create rigid intermediate structures that would produce isotherms with uptakes located between those of the lp and $n p$ forms to simulate various external pressures applied to the material. However, if the predictions are not satisfactory, then the goal is to fine-tune some of the force field parameters to improve the capture of our experimental data's behavior.

\subsection{Computational methodology}

\subsection{Charge distribution}

The initial atomic coordinates for the large pore (lp) and narrow pore (np) forms of the MIL53(Al) framework were taken directly from the structure's crystallographic information files (cif) obtained by X-ray diffraction. Table I shows the crystallographic cell parameters for the structure and the references from which they were obtained.

Table I: Crystallographic data for MIL-53(Al) structure used in this paper's calculations

\begin{tabular}{ccc}
$\begin{array}{c}\text { Crystallographic } \\
\text { data }\end{array}$ & \multicolumn{2}{c}{ MIL-53(Al) } \\
\hline & large pore $^{8}$ & narrow pore \\
a & 6.6085 & 19.716 \\
b & 16.675 & 8.310 \\
\hline
\end{tabular}




\begin{tabular}{ccc}
\hline $\mathrm{c}$ & 12.813 & 6.805 \\
$\alpha$ & 90.000 & 90.000 \\
$\beta$ & 90.000 & 105.85 \\
$\gamma$ & 90.000 & 90.000 \\
Space group & Imma (no 74) & $\mathrm{C} 2 / \mathrm{c}($ no 15$)$ \\
\hline
\end{tabular}

Since the positions of the $\mathrm{H}$ atoms are not detectable by experimental techniques, they were added to the framework's organic group using Accelrys Materials Studio 8.0's Visualizer software [ref Accelrys] ${ }^{10}$. The $\mu_{2}$ positions' $\mathrm{H}$ atoms were added by editing the structures' cif files. The periodic models were then geometry optimized with Accelrys' Dmol ${ }^{3}$ module [ref Accelrys], using the crystallographic coordinates of the atoms as starting configurations. With the same module, the partial charges for the porous structures were then extracted using density functional theory (DFT) calculations and the Mulliken charge partitioning method ${ }^{11}$ The obtained charges are presented in Table II. The calculations were performed using the PW91 GGA density functional ${ }^{12}$ and the double numerical basis set containing polarisation functions on the hydrogen atoms (DNP) [Hehre, W. J., Ditchfield, J.H., Pople, J.A, J. Chem Phys., 1972, 56, 2257]. Charges on the $\mathrm{CO}_{2}$ molecule, which was represented by an atomic point charge model, were taken from Yung and Harris' model ${ }^{13}$ It is important to note that the $\mathrm{C}-\mathrm{O}$ distance in the $\mathrm{CO}_{2}$ molecule was set to $1.149 \AA^{7}$ and not the $1.51 \AA$ that is set by default by the software.

Table II: Atomic partial charges carried by the different atoms in the open and closed forms of MIL53(Al), and in the $\mathrm{CO}_{2}$ molecule in electron units. The framework and $\mathrm{CO}_{2}$ molecule labels are described in Figure 1.

\begin{tabular}{ccccccccc} 
Atoms & h_c & cg1 & cg2 & c_c & o_c & $\mu_{-}$o & h_o & Al \\
\hline MIL-53(Al) $l p$ & 0.139 & -0.07 & -0.083 & 0.584 & -0.557 & -0.712 & 0.299 & 1.392 \\
MIL-53(Al) $n p$ & 0.134 & -0.071 & -0.077 & 0.566 & -0.562 & -0.741 & 0.292 & 1.478 \\
\hline
\end{tabular}

\begin{tabular}{ccc} 
Atoms & c_co2 & o_co2 \\
\hline $\mathrm{CO}_{2}$ & $0.6512^{13}$ & $-0.3256^{13}$ \\
\hline
\end{tabular}




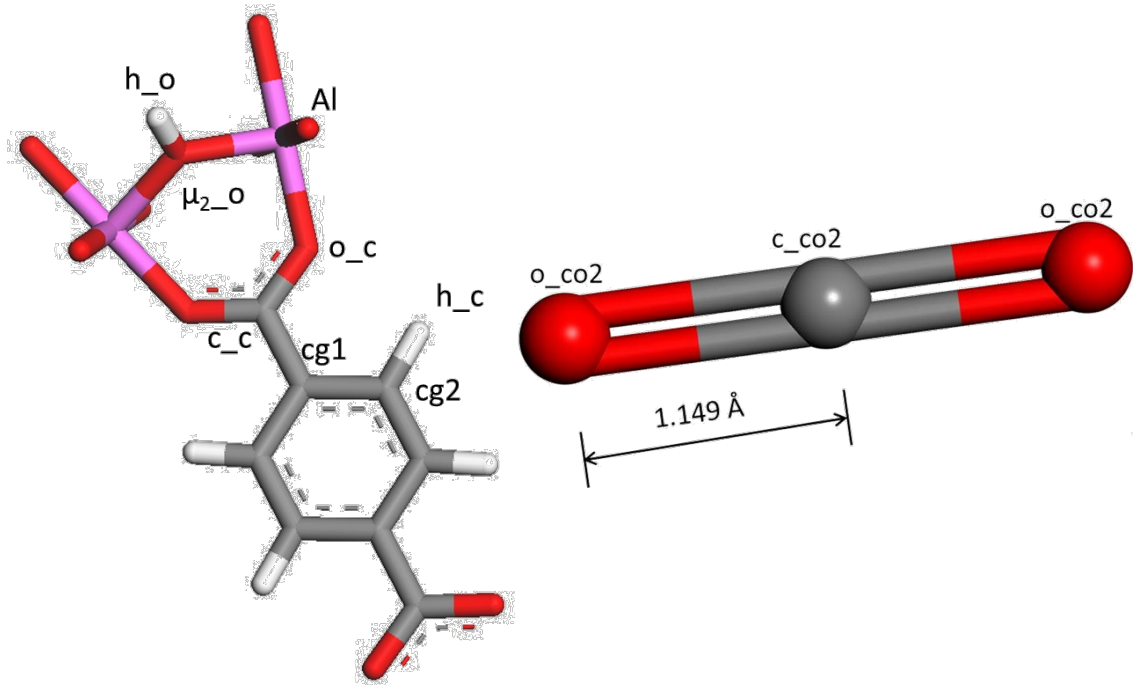

Figure 1. Labels of the force field types corresponding to each atom of the MIL-53(Al) structure and the $\mathrm{CO}_{2}$ molecule.

\subsection{Interatomic interactions}

The total energy (E) is expressed as the sum of the interaction energies between the adsorbate and the framework $\left(\mathrm{E}_{\mathrm{AF}}\right)$ and that between the adsorbate molecules $\left(\mathrm{E}_{\mathrm{AA}}\right)^{14}$ :

$$
E=E_{A F}+E_{A A}
$$

$\mathrm{E}_{\mathrm{AF}}$ and $\mathrm{E}_{\mathrm{AA}}$ are sums of pairwise additive potentials of the form:

$$
e_{i j}=4 \varepsilon_{i j}\left[\left(\frac{\sigma_{i j}}{r_{i j}}\right)^{12}-\left(\frac{\sigma_{i j}}{r_{i j}}\right)^{6}\right]+\frac{q_{i} q_{j}}{r_{i j}}
$$

where $\mathrm{e}_{\mathrm{ij}}$ is the sum of the non-bonded energetic interactions for $\mathrm{E}_{\mathrm{AF}}$ and $\mathrm{E}_{\mathrm{AA}}$. The first term in Eq (2) is the usual repulsion-dispersion Lennard-Jones (LJ) potential with $\varepsilon_{\mathrm{ij}}$ and $\sigma_{\mathrm{ij}}$ representing the potential well and the distance at which the potential between particles $\mathrm{i}$ and $\mathrm{j}$ is zero respectively, and $r_{i j}$ is the distance between the particles. The second term is the Coulombic contribution term accounting for electrostatic interactions between the particles, with $\mathrm{q}_{\mathrm{i}}$ and $\mathrm{q}_{\mathrm{j}}$ being the point charges for particles $\mathrm{i}$ and $\mathrm{j}$ respectively. The Lorentz-Berthelot mixing rules were applied in order to calculate the parameters for each pair of atoms:

$$
\begin{aligned}
\sigma_{i j} & =\frac{\sigma_{i}+\sigma_{j}}{2} \\
\varepsilon_{i j} & =\sqrt{\varepsilon_{i} \varepsilon_{j}}
\end{aligned}
$$


The LJ potential term in Eq (2) can also be expressed in the following form, more appropriate for calculations:

$$
e(L J)_{i j}=D 0_{i j}\left[\left(\frac{R 0_{i j}}{r_{i j}}\right)^{12}-\left(\frac{R 0_{i j}}{r_{i j}}\right)^{6}\right]
$$

where $\mathrm{R} 0_{\mathrm{ij}}=\sigma_{\mathrm{ij}}{ }^{*}{ }^{1 / 6}$ represents the distance at which the potential well is at its maximum absolute value of depth and $\mathrm{D} 0_{\mathrm{ij}}$ is the potential well in units of $\mathrm{kCal} \mathrm{mol}^{-1}$. Table III presents the LJ interaction parameters used in this work. Parameters for the $\mathrm{CO}_{2}-\mathrm{MOF}$ interactions were calculated with Eqs (3) and (4) from the LJ parameters for each atom type used by Hamon et al ${ }^{15}$. In their work, the parameters describing the atoms in the organic part of the structure were taken from the Dreiding force field ${ }^{16}$ and those describing the atoms in the inorganic part come from the Universal Force Field (UFF) ${ }^{17}$. Parameters for the $\mathrm{CO}_{2}-\mathrm{CO}_{2}$ interactions were again calculated with the Lorentz-Berthelot mixing rules with LJ parameters for each atom taken from Yung and Harris ${ }^{13}$. To our knowledge, this force field is the most accurate for the simulation of $\mathrm{CO}_{2}$ adsorption on the MIL-53 family of frameworks and was frequently and successfully used to explain the breathing behavior of these flexible frameworks ${ }^{1,2,10,15}$.

Table III: Repulsion-dispersion Lennard-Jones parameters for each interacting pair of the adsorbentadsorbate interaction. The parameters were taken from Ref. 15.

\begin{tabular}{|c|c|c|}
\hline Adsorbent-adsorbate pair & $\mathrm{D} 0_{\mathrm{ij}}, \mathrm{kCal} \mathrm{mol}^{-1}$ & $\mathrm{R} 0_{\mathrm{ij}}, \AA$ \\
\hline c_c - c_co2 & 0.073056 & 3.5004 \\
\hline c_c-o_co2 & 0.12374 & 3.6553 \\
\hline $\operatorname{cg} 1-\mathrm{c} \_\mathrm{co} 2$ & 0.073056 & 3.5004 \\
\hline cg1-o_co2 & 0.12374 & 3.6553 \\
\hline cg2 - c_co2 & 0.073056 & 3.5004 \\
\hline cg2 - o_co2 & 0.12374 & 3.6553 \\
\hline h_c - o_co2 & 0.049286 & 3.2849 \\
\hline h_o - c_co2 & 0 & 1.5473 \\
\hline h_o-o_co2 & 0 & 1.7022 \\
\hline$\mu_{2}-0-c \_c 02$ & 0.057756 & 3.2984 \\
\hline$\mu_{2} \mathrm{o}-\mathrm{o} \_\mathrm{co} 2$ & 0.097822 & 3.4533 \\
\hline O_c - c_co2 & 0.057756 & 3.2984 \\
\hline o_c - o_co2 & 0.097822 & 3.4533 \\
\hline
\end{tabular}

Table IV: Repulsion-dispersion Lennard-Jones parameters for each interacting pair of the adsorbateadsorbate interaction. The parameters were taken from Ref. 13.

\begin{tabular}{ccc} 
Adsorbate-adsorbate pair & $\mathrm{D}_{0} \mathrm{in}_{\mathrm{i}}, \mathrm{kCal} \mathrm{mol}^{-1}$ & $\mathrm{R} 0_{\mathrm{ij}}, \AA$ \\
\hline c_co2 - c_co2 & 0.055782 & 3.0946 \\
c_co2 - o_co2 & 0.094478 & 3.2495 \\
\hline
\end{tabular}




o_co2 - o_co2 $\quad 0.16002 \quad 3.4044$

\subsection{Grand Canonical Monte Carlo (GCMC) simulations}

Absolute adsorption isotherms were computed using the GCMC algorithm implemented in Accelrys' Sorption module (ref Accelrys), which allows exchange, displacement (translation and rotation), regrowth and conformer moves ${ }^{18}$. These simulations consist of evaluating, for a given volume and temperature, the average number of adsorbate molecules whose chemical potential is equal to that of the bulk fluid. All simulations in this work were run at $303 \mathrm{~K}$, using one unit cell for the np and lp forms of the MIL-53(Al) framework. Characteristically, 1 $\mathrm{x} 10^{7}$ Monte Carlo (MC) steps were used for each run, the frameworks of both structures being considered rigid. The electrostatic interactions were taken into account by using the Ewald summation and the short range interactions were limited to a cut-off distance of $12 \AA^{19}$.

\section{Results and discussion}

Fig. 2 shows the GCMC simulations for $\mathrm{CO}_{2}$ uptake and enthalpy of adsorption in the MIL53(Al) framework at $303 \mathrm{~K}$. The LJ parameter values used for these simulations are taken from tables III and IV. In Fig. 2 a, although the equilibration values for the isotherms seem to be in the right range of values ( 8 and $2 \mathrm{mmol} \mathrm{g}^{-1}$ for the $1 \mathrm{p}$ and $\mathrm{np}$ forms respectively) the gasframework interaction appears to be too strong, resulting in a steep uptake slope for both forms at low fugacity. As stated by Ramsahye et al ${ }^{1}$ and mentioned above, between 0.25 and 6 bar the $\mathrm{np}$ form is the most energetically preferred form for $\mathrm{CO}_{2}$ adsorption on MIL-53(Al). Our experimental values show that for a fugacity of $0.25 \mathrm{bar}$, the $\mathrm{CO}_{2}$ uptake is $0.5 \mathrm{mmol} \mathrm{g}$ whereas the simulations show an almost fourfold adsorbed value of $1.89 \mathrm{mmol} \mathrm{g}^{-1}$ for the $\mathrm{np}$ form (Fig. 2 c). Also, for both forms of simulated isotherms, saturation seems to occur at low fugacity values while experimentally $\mathrm{CO}_{2}$ molecules are still being adsorbed in the framework's pores at fugacities well over 10 bar. Fig. 2 b shows the simulated enthalpy of adsorption for both forms of the MIL-53(Al) structure. It can be seen that although the np form's values display a relatively flat behavior and are in the higher than expected $40 \mathrm{~kJ} \mathrm{~mol}^{-1}$ range ${ }^{1,19}$, the $1 \mathrm{p}$ form's increase from around $20 \mathrm{~kJ} \mathrm{~mol}^{-1}$ to $35 \mathrm{~kJ} \mathrm{~mol}^{-1}$ denotes uncharacteristically strong $\mathrm{CO}_{2}-\mathrm{CO}_{2}$ interactions and excessively high energy values. Fig. $2 \mathrm{~d}$ compares our experimental data for enthalpy of adsorption to the simulated values and clearly demonstrates the gap between the two. In the light of these results, we conclude that in our case the initial parameter values found in the literature do not produce an adequate prediction of $\mathrm{CO}_{2}$ adsorption in the MIL-53(Al) framework. The reasons for this are not quite clear, as 
the same software and same simulation conditions as in ${ }^{1,2,10,15}$ were followed and the structures were taken from the same references ${ }^{8,9}$. Differences between the experimental data found in the literature and those obtained in this work can however be attributed to density variations between batches, quantities used and accumulated experimental error with increasing pressure. Since it appears from Fig. $2 \mathrm{~b}$ that the enthalpy of adsorption for both $1 p$ and $n p$ forms of the structure is too high, we have tried to manually alter the $\mathrm{R} 0_{\mathrm{ij}}$ and $\mathrm{D} 0_{\mathrm{ij}}$ parameters for the $\mathrm{CO}_{2}-\mathrm{CO}_{2}$ interactions, without touching the $\mathrm{CO}_{2}-\mathrm{MOF}$ interaction parameters. Furthermore, we have chosen not to modify the electrostatic interactions since the charges for the structure were obtained from our own DFT calculations and Mulliken charge partitioning method, and not taken from the literature. Electrostatic charges for the c_co2, o_co2 atoms were left unmodified as well. This strategy is rather unconventional but it was our thinking that the various modifications of the $\mathrm{R} 0_{\mathrm{ij}}$ and $\mathrm{D} 0_{\mathrm{ij}}$ parameters for the $\mathrm{CO}_{2}-\mathrm{CO}_{2}$ interactions would give some valuable information about the extent of their sole influence on the adsorption isotherms and the enthalpy of adsorption.

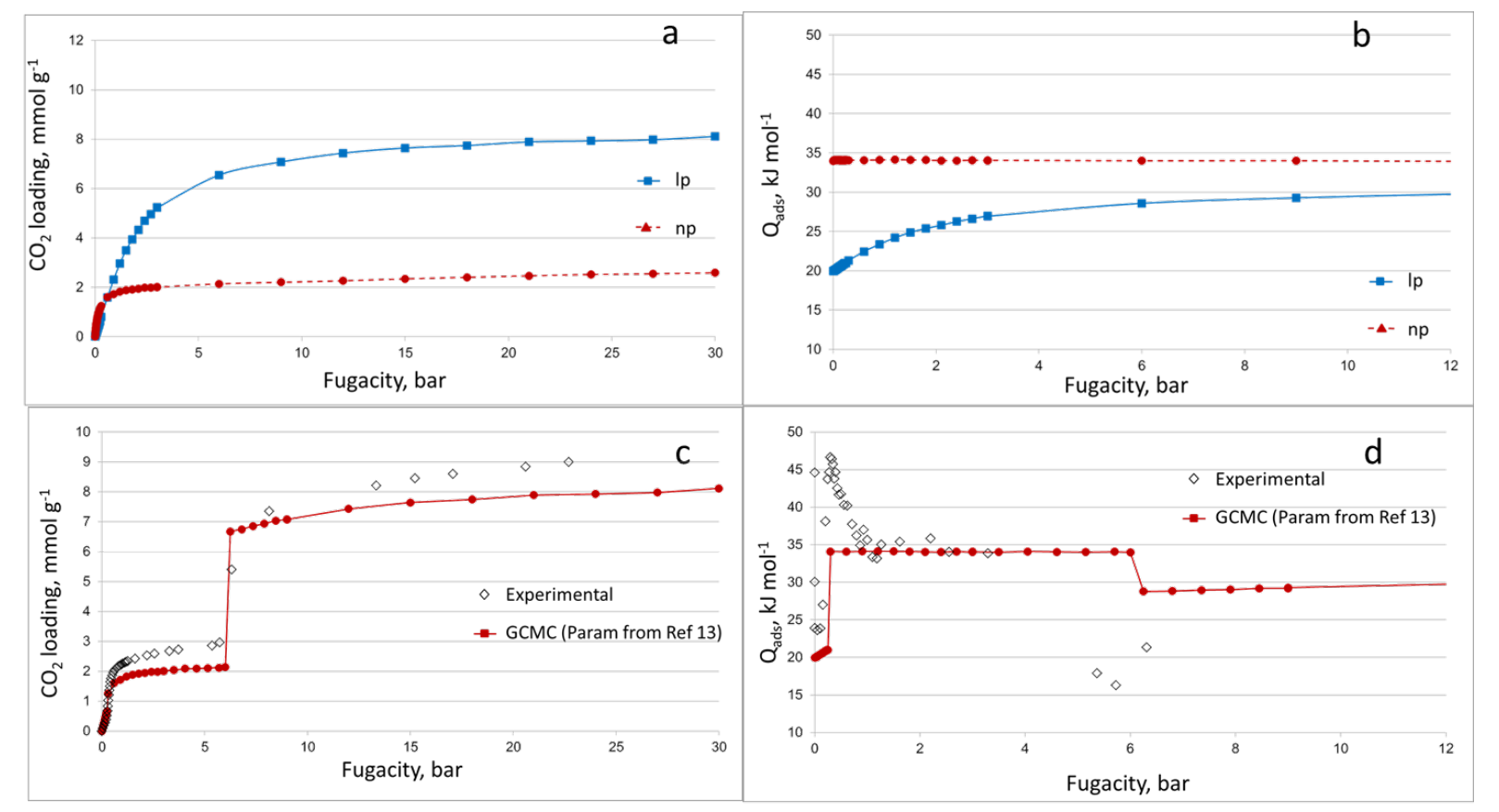

Figure 2. GCMC simulations of (a) $\mathrm{CO}_{2}$ adsorption isotherms (b) enthalpy of adsorption on MIL53(Al) at $303 \mathrm{~K}$ using $\mathrm{CO}_{2}-\mathrm{CO}_{2}$ interaction parameters from Ref 13. Figures (c) and (d) compare the simulated combinations of $\mathrm{lp}$ and $\mathrm{np}$ forms to experimental data.

In order to get a sense of the dependence of the isotherms and the enthalpy of adsorption on the interaction between the $\mathrm{CO}_{2}$ molecules, we first varied the $\mathrm{D} 0_{\mathrm{ij}}$ parameters by adding or subtracting $80 \%$ of their value while keeping $\mathrm{R} 0_{\mathrm{ij}}$ constant. Then we kept the $\mathrm{D} 0_{\mathrm{ij}}$ parameters at their original values and varied the $\mathrm{R} 0_{\mathrm{ij}}$ parameters by $20 \%$ and $80 \%$ of their value. The 
parameter values for variations in $\mathrm{D} 0_{\mathrm{ij}}$, and $\mathrm{R} 0_{\mathrm{ij}}$ are shown in Tables $\mathrm{V}$ and VI respectively, while Figures 3 and 4 show variations in $\mathrm{CO}_{2}$ uptake and enthalpy of adsorption due to changes in $\mathrm{D} 0_{\mathrm{ij}}$,and $\mathrm{R} 0_{\mathrm{ij}}$ respectively.

Table V: Variation of the repulsion-dispersion Lennard-Jones parameter $\mathrm{D} 0_{\mathrm{ij}}$ for each interacting pair of the adsorbate-adsorbate interaction.
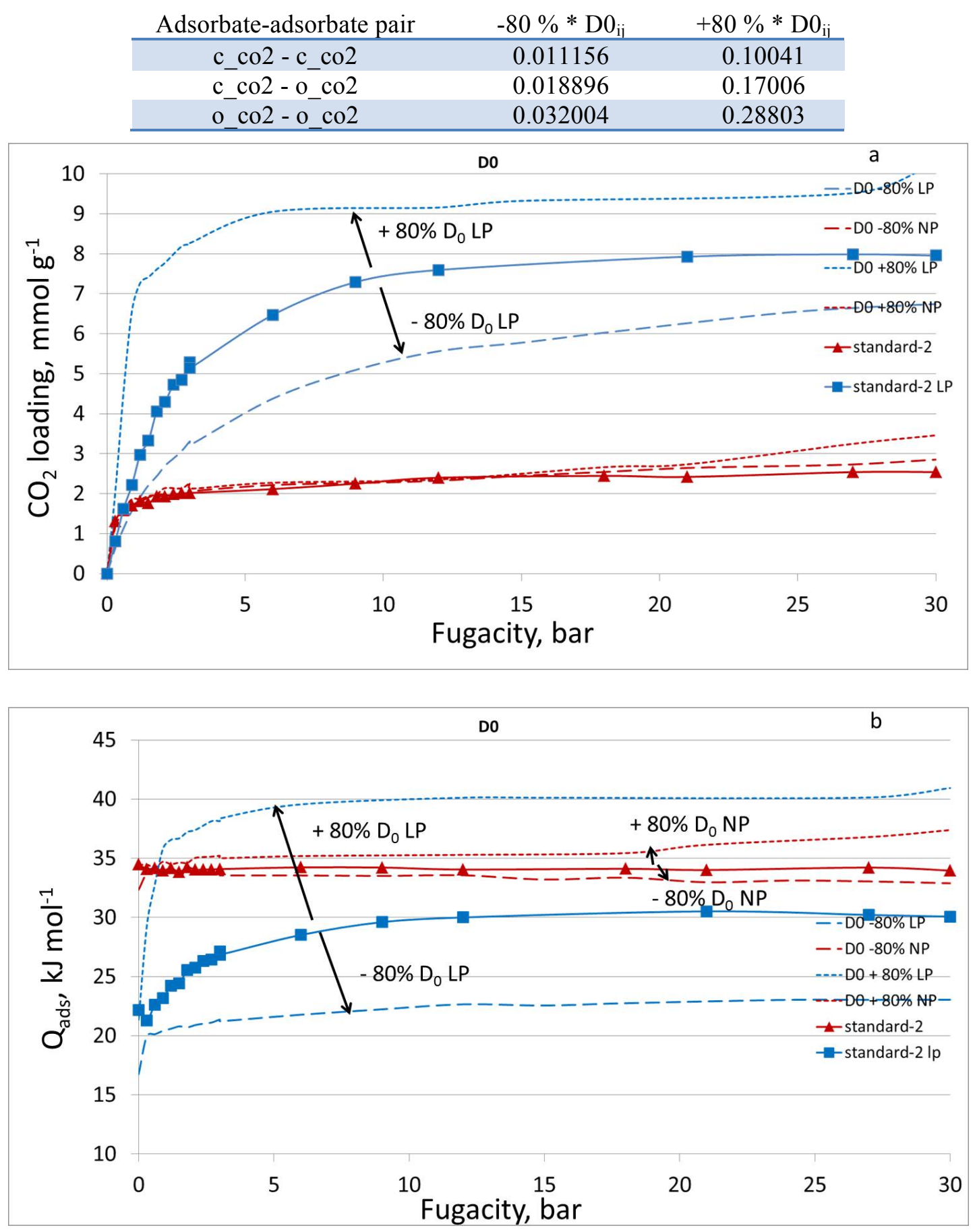
Figure 3. GCMC simulations of (a) $\mathrm{CO}_{2}$ adsorption isotherms and (b) enthalpy of adsorption on MIL$53(\mathrm{Al})$ at $303 \mathrm{~K}$ using variations of $\mathrm{D} 0_{\mathrm{ij}}$ parameters for $\mathrm{CO}_{2}-\mathrm{CO}_{2}$ interactions.

Table VI: Variation of the repulsion-dispersion Lennard-Jones parameter $\mathrm{R} 0_{\mathrm{ij}}$ for each interacting pair of the adsorbate-adsorbate interaction.

\begin{tabular}{ccccc} 
Adsorbate-adsorbate pair & $-80 \% * \mathrm{R} 0_{\mathrm{ij}}$ & $-20 \% * \mathrm{R} 0_{\mathrm{ij}}$ & $+20 \% * \mathrm{R} 0_{\mathrm{ij}}$ & $+80 \% * \mathrm{R} 0_{\mathrm{ij}}$ \\
\hline c_co2 - c_co2 & 0.61893 & 2.4757 & 3.7135 & 5.5703 \\
c_co2-o_co2 & 0.64991 & 2.5996 & 3.8994 & 5.8491 \\
o_co2-o_co2 & 0.68088 & 2.7235 & 4.0853 & 6.1279 \\
\hline
\end{tabular}
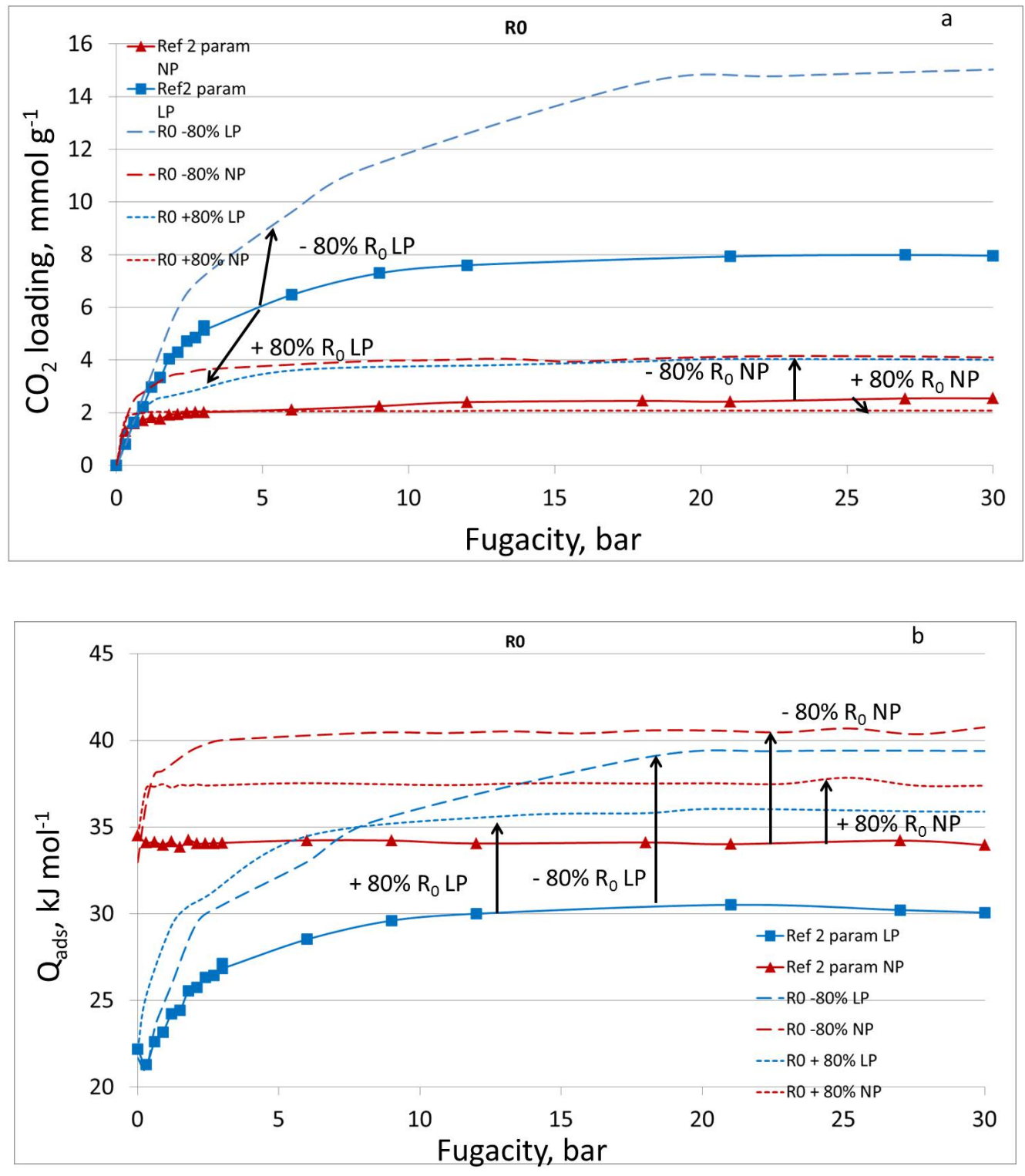

Figure 4. GCMC simulations of (a) $\mathrm{CO}_{2}$ adsorption isotherms and (b) enthalpy of adsorption on MIL$53(\mathrm{Al})$ at $303 \mathrm{~K}$ using variations of $\mathrm{R} 0_{\mathrm{ij}}$ parameters for $\mathrm{CO}_{2}-\mathrm{CO}_{2}$ interactions. 


\section{Influence of D0}

Figure 3a shows us that the variation of the energetic D0 parameter produces what we would intuitively expect: by reducing this parameter value, the interactions between the $\mathrm{CO}_{2}$ molecules decrease and result in a lower uptake than what was obtained with the original D0 value (Table IV). This behavior is much more evident for the LP form than for the NP form due to the steric effect of the latter. Indeed, in the NP configuration there is less space for the molecules to move around so the impact of reduction of the energetic interaction between adsorbate molecules is less striking. By increasing the D0 parameter the expected increase in adsorbed molecules occurs as well as a more pronounced slope at low pressure, suggesting high adsorbate-adsorbent interaction. This is probably due to the higher number of $\mathrm{CO}_{2}$ molecules being clustered together, taking up more space and yielding higher enthalpy of adsorption. As was the case for the decrease in D0, the effect of the increase of this parameter is not obvious for the NP form of the structure because of the lack of space. These characteristics of $\mathrm{CO}_{2}$ uptake variations due to changes in the D0 parameter can also be seen on Figure $3 \mathrm{~b}$ where the enthalpy of adsorption is plotted as a function of fugacity. It is noticed that for the three parameter values of the LP form, the enthalpy of adsorption spans a much larger energy spectrum than that for the NP form. For the NP form, the three parameter values do not have a big influence on the enthalpy of adsorption, meaning that whether we increase or decrease D0 by $80 \%$ of its value or we leave it as it is, the energy released by the adsorbate due to adsorption on the pore walls remains arguably the same.

\section{Influence of R0}

Figure 4 illustrates the influence of the $\mathrm{R} 0$ parameter on $\mathrm{CO}_{2}$ uptake and enthalpy of adsorption. It can be seen from Figure $4 \mathrm{a}$ that as the equilibrium distance parameter R0 decreases, uptake is increased because of the reduction of the repulsion and increase in the dispersion contributions of the $\mathrm{LJ}$ potential, thus allowing $\mathrm{CO}_{2}$ molecules to come closer together. Consequently, increasing R0 increases the repulsion and decreases the dispersion contributions of the $\mathrm{LJ}$ potential and keeps clusters of $\mathrm{CO}_{2}$ molecules from forming, lowering the amount of adsorbed molecules in the pore. This behavior is detected for both LP and NP forms, the latter being less pronounced than the former, although decreasing R0 by $80 \%$ of its value seems to have a more significant impact on the uptake than increasing it. An interesting 
phenomenon is observed when we look at the enthalpy of adsorption shown on Figure 4b: for both forms, the energy released due to adsorption is higher for both decreased and increased parameter values. Also, in both cases the enthalpy of increased R0 is smaller than the decreased one.

Table VII: Effects of the variation of the repulsion-dispersion Lennard-Jones parameters $\mathrm{D} 0_{\mathrm{ij}}$ on the $\mathrm{CO}_{2}$ uptake and enthalpy of adsorption

\begin{tabular}{ccc} 
Variable & $-80 \% * \mathrm{R}_{\mathrm{ij}}$ & $+80 \% * \mathrm{R}_{\mathrm{ij}}$ \\
\hline $\mathrm{CO}_{2}$ loading, $\mathrm{mmol} \mathrm{g}^{-1}$ & 0.61893 & 5.5703 \\
$\mathrm{Q}_{\mathrm{ads}}, \mathrm{kJ} \mathrm{mol}^{-1}$ & 0.64991 & 5.8491 \\
\hline
\end{tabular}

Table VIII: Effects of the variation of the repulsion-dispersion Lennard-Jones parameters $\mathrm{R} 0_{\mathrm{ij}}$ on the $\mathrm{CO}_{2}$ uptake and enthalpy of adsorption

\begin{tabular}{ccccc} 
Variable & $-80 \% * \mathrm{R}_{\mathrm{ij}}$ & $-20 \% * \mathrm{R} 0_{\mathrm{ij}}$ & $+20 \% * \mathrm{R} 0_{\mathrm{ij}}$ & $+80 \% * \mathrm{R}_{\mathrm{ij}}$ \\
\hline $\mathrm{CO}_{2}$ loading, $\mathrm{mmol} \mathrm{g}^{-1}$ & 0.61893 & 2.4757 & 3.7135 & 5.5703 \\
$\mathrm{Q}_{\text {ads }}, \mathrm{kJ} \mathrm{mol}^{-1}$ & 0.64991 & 2.5996 & 3.8994 & 5.8491 \\
\hline
\end{tabular}

Figure 3. GCMC simulations of (a) $\mathrm{CO}_{2}$ adsorption isotherms and (b) enthalpy of adsorption on MIL$53(\mathrm{Al})$ at $303 \mathrm{~K}$ using variations of $\mathrm{LJ}$ parameters for $\mathrm{CO}_{2}-\mathrm{CO}_{2}$ interactions.

Thus, for a case where the energy between the adsorbate molecules is too high, a decrease in both $\mathrm{R} 0_{\mathrm{ij}}$ and $\mathrm{D} 0_{\mathrm{ij}}$ parameters contributes in obtaining a better fit to the experimental data. After many modifications of the c_co 2 - c_co 2 and o_co 2 - o_co2 interactions (the third interaction parameters c_co2 - o_co2 are calculated using the Lorentz-Berthelot mixing rule once values for the first two are set), we obtained the optimal parameters shown in Table IX. The isotherms and enthalpies of adsorption with the modified $\mathrm{CO}_{2}-\mathrm{CO}_{2}$ parameters are shown in Fig. 5.

Table IX: Manually modified repulsion-dispersion Lennard-Jones parameters for each interacting pair of the adsorbate-adsorbate interaction. 


\begin{tabular}{ccc}
$\begin{array}{c}\text { Adsorbate-adsorbate } \\
\text { pair }\end{array}$ & $\begin{array}{c}\mathrm{D} 0_{\mathrm{ij}}, \mathrm{kCal} \mathrm{mol}^{-1} \\
\text { (this work) }\end{array}$ & $\begin{array}{c}\mathrm{R} 0_{\mathrm{ij}}, \AA \\
\text { (this work) }\end{array}$ \\
\hline c_co2 - c_co2 & 0.01 & 2.80 \\
c_co2 - o_co2 & 0.01732 & 2.90 \\
O_co2 - o_co2 & 0.03 & 3.00 \\
\hline
\end{tabular}
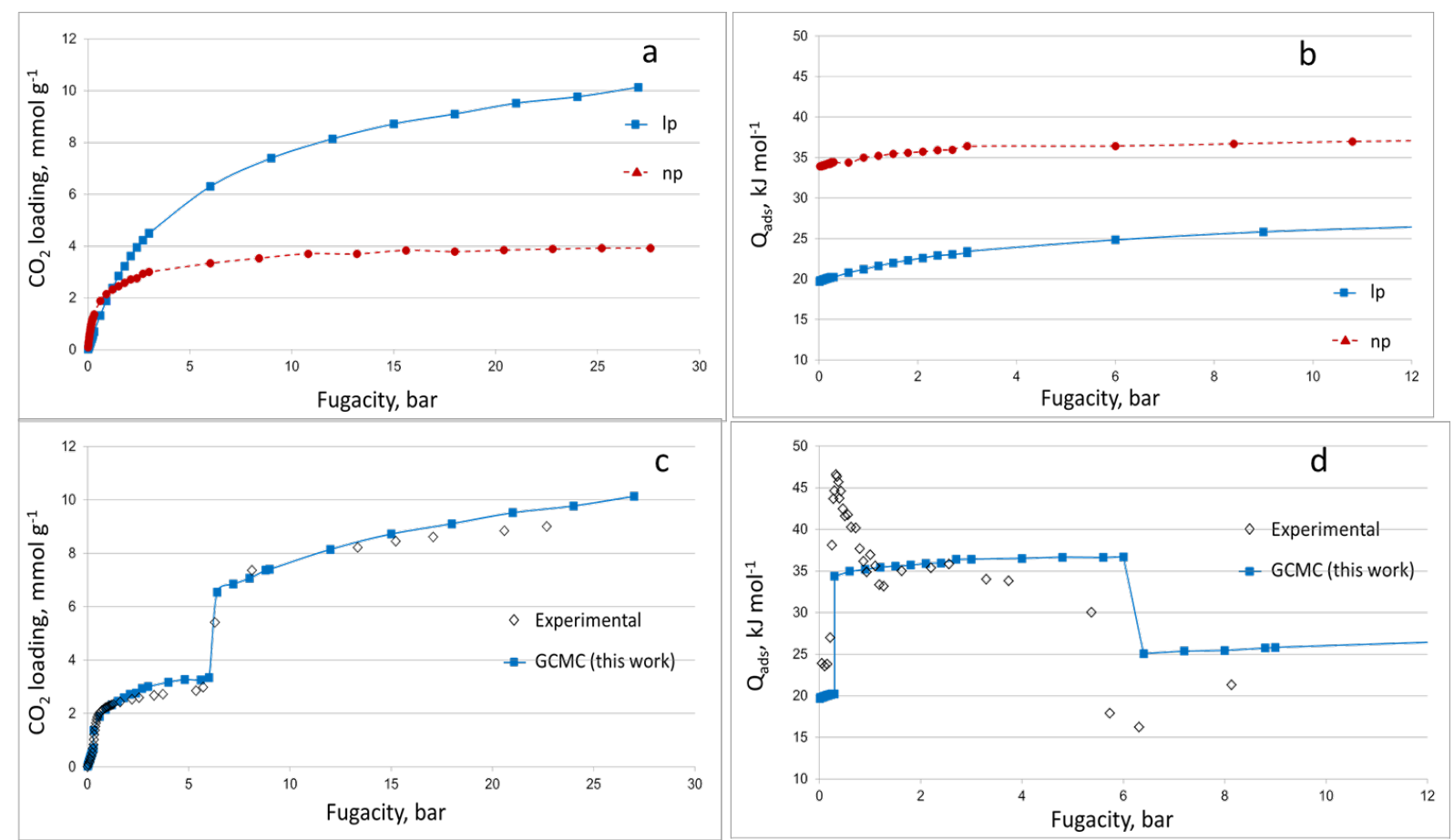

Figure 5. GCMC simulations of (a) $\mathrm{CO}_{2}$ adsorption isotherms (b) enthalpy of adsorption on MIL53(Al) at $303 \mathrm{~K}$ using our most accurate manually fitted $\mathrm{CO}_{2}-\mathrm{CO}_{2}$ interaction parameters. (c) and (d) compare the simulated combinations of $\mathrm{lp}$ and $\mathrm{np}$ forms to our experimental data. 


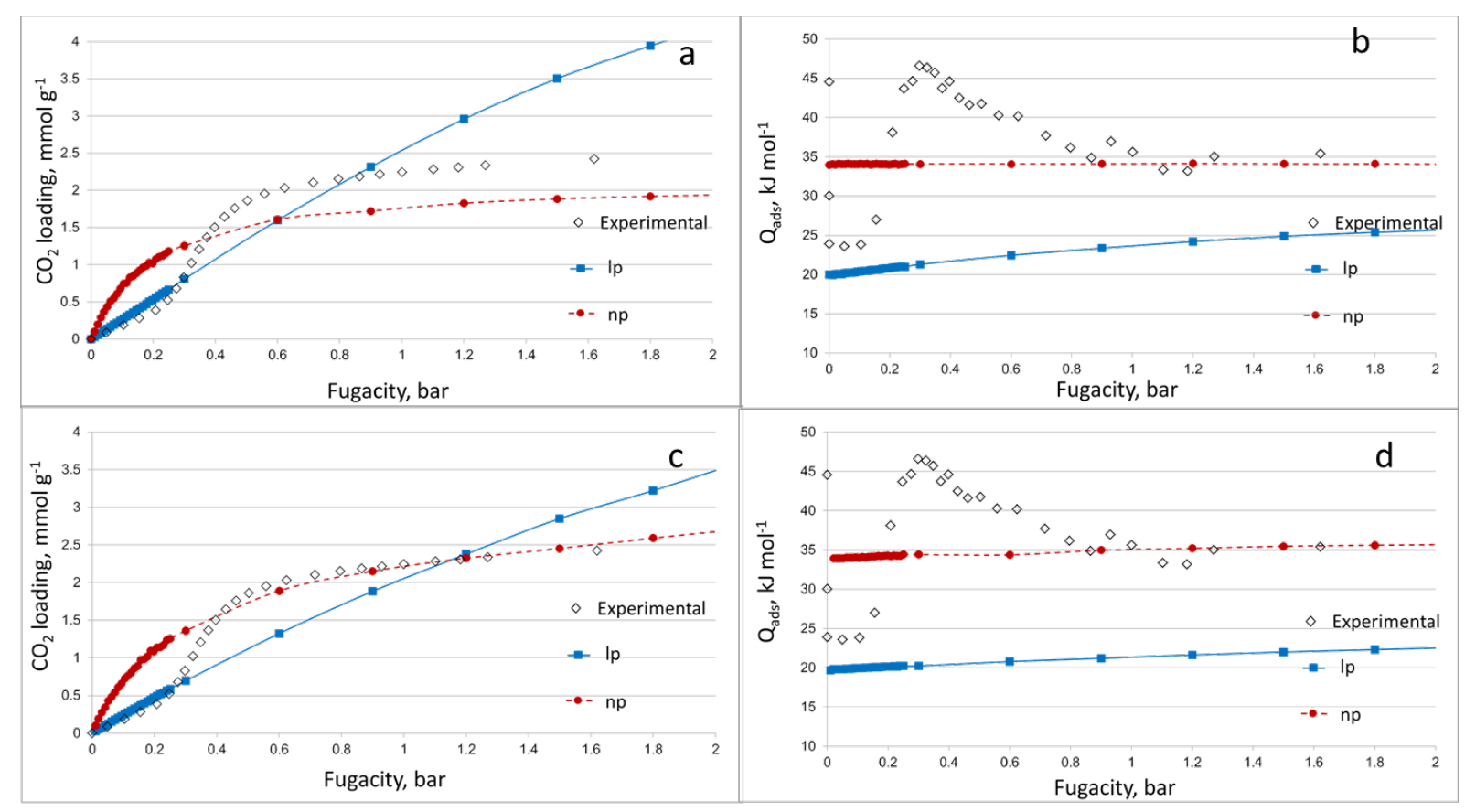

Figure 6. Comparison between low pressure GCMC simulations of $\mathrm{CO}_{2}$ adsorption isotherms and enthalpy of adsorption on lp and np forms of the MIL-53(Al) structure at $303 \mathrm{~K}$. (a) and (b) are the initial $\mathrm{CO}_{2}-\mathrm{CO}_{2}$ interaction parameters found in the literature and (c)and (d) are the manually fitted parameters we have used in this work.

\section{Conclusions}

A generic force field with parameters widely used in literature was implemented to predict experimental adsorption data for $\mathrm{CO}_{2}$ on MIL-53(Al) framework's open (lp) and closed (np) forms. However, the accuracy of the predictions was not satisfying with regard to our experimental isotherms and the calorimetrically measured enthalpy of adsorption. The main problems in the predictions with the original parameters were the large increase in enthalpy of adsorption with increasing pressure, and failure to capture the isotherms' shapes. Therefore, attempts were undertaken to study the susceptibility of the calculated properties to parameters' variations, and to fine-tune the LJ potential parameters, equilibrium distance R0, and energetic parameter D0, for the $\mathrm{CO}_{2}$ molecule's carbon and oxygen atoms. First, a sensitivity analysis regarding the $\mathrm{CO}_{2} \mathrm{LJ}$ parameters D0 and R0 was carried out. Four variations of $10 \%$ of the original $\mathrm{R} 0$ and $\mathrm{D} 0$ parameter values were tested, while keeping every other parameter in the force field constant: 10\% increases in D0 and R0, and 10\% decreases in D0 and R0. This simple analysis allowed us to quantify to what extent, and in which "direction," a $10 \%$ variation in the parameter values would modify the $\mathrm{CO}_{2}$ uptake and the energy generated by the adsorbed molecules. It followed from the analysis that a slight decrease in each parameter (5\% and $7 \%$ in D0 and R0, respectively) improved the force field's prediction for the $\mathrm{CO}_{2}$ experimental data. 
It is important to note that our exploration of the parameter variations' impact is purely numerical. The low variation from the original parameters $(10 \%)$ tested in this work was part of the goal of keeping the changes physically sound. However, despite this precaution, the parameters that best predicted the experimental adsorption data in our work $(5 \%$ decrease in D0 and 7\% decrease in R0) were not able to reproduce the $\mathrm{CO}_{2}$ VLE curve accurately. It was found that variations of 5\% in the D0 parameter, and around $2 \%$ in the R0 parameter should not be exceeded. Manual iterations in order to obtain an optimal combination of D0 and R0 parameter values where the adsorption experimental data would be better predicted while keeping the nature of the $\mathrm{CO}_{2}$ molecule physically sound are possible but can prove laborious. The discussed results confirm our hypothesis that adsorption of $\mathrm{CO}_{2}$ in MIL-53 MOF structure is very sensitive to structural parameters. Moreover, unless the desired changes from the employed force field's original parameters are relatively small, manual fine-tuning of LJ parameters should be done with extreme caution, and, very importantly, validated for physical soundness.

One possible factor that could be important for the quality of the force field is that of multibody effects. Indeed their influence was not verified for $\mathrm{CO}_{2}$ as the initial force field does not take them into account in the pairwise parameterization process. Therefore, it is in fact very likely that including a many-body contribution would explain some of the discrepancies, and result in both an appropriate VLE curve and a better uptake/enthalpy of adsorption prediction. As suggested in recent work, taking into account many-body interactions can result in sharp changes in the grand-canonical partition functions of single-component systems and nanoconfined fluids, considerably deviating adsorption properties like isotherms and heats of adsorption $[24,25]$. Although not in the present paper because of the necessity to modify the whole $\mathrm{CO}_{2}$ model, which will require a non-negligible amount of time, it is definitely something that we should look into in the very near future, and is an excellent path to follow to answer some of the questions that have arisen in this work.

\section{References}

[1] Kikuchi, R. Energ. Environ. 2003, 14(4), 383.

[2] Peppley, B. A., Int. J. Green Energy, 2006, 3(2), 201.

[3] Ramsahye, N. A.; Maurin, G.; Bourrelly, S.; Llewellyn, P. L.; Loiseau, T.; Serre, C.; Férey, G. Chem. Commun. 2007, No. 31, 3261.

[4] Beurroies, I.; Boulhout, M.; Llewellyn, P. L.; Kuchta, B.; Férey, G.; Serre, C.; Denoyel, R. Angew. Chem. Int. Ed. 2010, 49 (41), 7526. 
(Dmol3, v. 4.0; Accelrys, Inc.: San Diego, 2005)

(1) Ramsahye, N. A.; Maurin, G.; Bourrelly, S.; Llewellyn, P. L.; Loiseau, T.; Serre, C.; Férey, G. Chem. Commun. 2007, No. 31, 3261.

(2) Salles, F.; Ghoufi, A.; Maurin, G.; Bell, R. G.; Mellot-Draznieks, C.; Férey, G. Angew. Chem. Int. Ed. 2008, 47 (44), 8487.

(3) Schneemann, A.; Bon, V.; Schwedler, I.; Senkovska, I.; Kaskel, S.; Fischer, R. A. Chem Soc Rev 2014, 43 (16), 6062.

(4) Serre, C.; Millange, F.; Thouvenot, C.; Noguès, M.; Marsolier, G.; Louër, D.; Férey, G. J. Am. Chem. Soc. 2002, 124 (45), 13519.

(5) Zhao, X.; Xiao, B.; Fletcher, A. J.; Thomas, K. M.; Bradshaw, D.; Rosseinsky, M. J. Science 2004, 306 (5698), 1012.

(6) Bourrelly, S.; Llewellyn, P. L.; Serre, C.; Millange, F.; Loiseau, T.; Férey, G. J. Am. Chem. Soc. 2005, 127 (39), 13519.

(7) García-Pérez, E.; Serra-Crespo, P.; Hamad, S.; Kapteijn, F.; Gascon, J. Phys. Chem. Chem. Phys. 2014, 16 (30), 16060.

(8) Loiseau, T.; Serre, C.; Huguenard, C.; Fink, G.; Taulelle, F.; Henry, M.; Bataille, T.; Férey, G. Chem. - Eur. J. 2004, 10 (6), 1373.

(9) Serre, C.; Bourrelly, S.; Vimont, A.; Ramsahye, N. A.; Maurin, G.; Llewellyn, P. L.; Daturi, M.; Filinchuk, Y.; Leynaud, O.; Barnes, P.; Férey, G. Adv. Mater. 2007, 19 (17), 2246.

(10) Ramsahye, N. A.; Maurin, G.; Bourrelly, S.; Llewellyn, P. L.; Serre, C.; Loiseau, T.; Devic, T.; Ferey, G. J. Phys. Chem. C 2008, 112 (2), 514.

(11) Mulliken, R. S. J. Chem. Phys. 1955, 23 (10), 1833.

(12) Perdew, J. P.; Yue, W. Phys. Rev. B 1986, 33 (12), 8800.

(13) Harris, J. G.; Yung, K. H. J. Phys. Chem. 1995, 99 (31), 12021.

(14) Maurin, G.; Llewellyn, P. L.; Bell, R. G. J. Phys. Chem. B 2005, 109 (33), 16084.

(15) Hamon, L.; Leclerc, H.; Ghoufi, A.; Oliviero, L.; Travert, A.; Lavalley, J.-C.; Devic, T.; Serre, C.; Férey, G.; De Weireld, G.; Vimont, A.; Maurin, G. J. Phys. Chem. C 2011, 115 (5), 2047.

(16) Mayo, S. L.; Olafson, B. D.; Goddard, W. A. J. Phys. Chem. 1990, 94 (26), 8897.

(17) Rappé, A. K.; Casewit, C. J.; Colwell, K. S.; Goddard III, W. A.; Skiff, W. M. J. Am. Chem. Soc. 1992, $114(25)$.

(18) Akkermans, R. L. C.; Spenley, N. A.; Robertson, S. H. Mol. Simul. 2013, 39 (14-15), 1153.

(19) Ramsahye, N. A.; Maurin, G.; Bourrelly, S.; Llewellyn, P.; Loiseau, T.; Ferey, G. Phys Chem Chem Phys 2007, 9 (9), 1059. 